
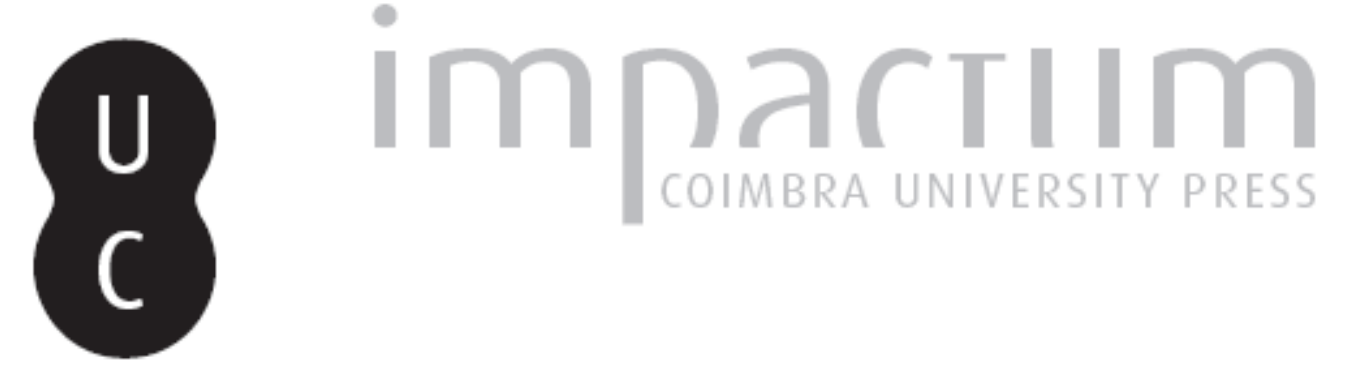

"É um dos pontos negros da biografia que não tive": reflexões acerca de um texto
autobiográfico de Fernando Pessoa com uma digressão sobre um erro na Ode
Marítima que as edições críticas não emendaram

Autor(es): $\quad$ Miraglia, Gianluca

Publicado por: Imprensa da Universidade de Coimbra

URL

persistente:

URI:http://hdl.handle.net/10316.2/42650

DOI:

DOI:https://doi.org/10.14195/0870-8584_2_16

Accessed : $\quad$ 26-Apr-2023 12:47:47

A navegação consulta e descarregamento dos títulos inseridos nas Bibliotecas Digitais UC Digitalis, UC Pombalina e UC Impactum, pressupõem a aceitação plena e sem reservas dos Termos e Condições de Uso destas Bibliotecas Digitais, disponíveis em https://digitalis.uc.pt/pt-pt/termos.

Conforme exposto nos referidos Termos e Condições de Uso, o descarregamento de títulos de acesso restrito requer uma licença válida de autorização devendo o utilizador aceder ao(s) documento(s) a partir de um endereço de IP da instituição detentora da supramencionada licença.

Ao utilizador é apenas permitido o descarregamento para uso pessoal, pelo que o emprego do(s) título(s) descarregado(s) para outro fim, designadamente comercial, carece de autorização do respetivo autor ou editor da obra.

Na medida em que todas as obras da UC Digitalis se encontram protegidas pelo Código do Direito de Autor e Direitos Conexos e demais legislação aplicável, toda a cópia, parcial ou total, deste documento, nos casos em que é legalmente admitida, deverá conter ou fazer-se acompanhar por este aviso. 


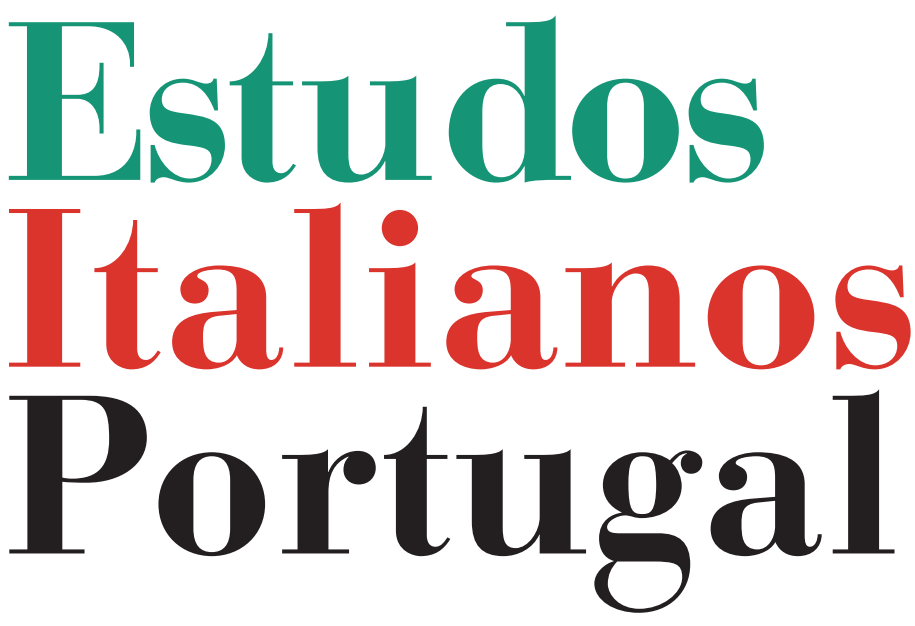

Instituto

Italiano

de Cultura

de Lisboa

Nova Série

$\mathbf{N}^{\mathbf{0}} 2$ 


\section{"É UM DOS PONTOS NEGROS DA BIOGRAFIA QUE NÃO TIVE": REFLEXÕES ACERCA \\ DE UM TEXTO AUTOBIOGRÁFICO \\ DE FERNANDO PESSOA \\ COM UMA DIGRESSÃO SOBRE UM ERRO \\ NA ODE MARÍTIMA QUE AS EDIÇÕES CRÍTICAS \\ NÃO EMENDARAM}

Gianluca Miraglia*

É notório Que a poesia inglesa de Fernando Pessoa tem desde sempre suscitado apreciações críticas discordes e, não raro, perplexidade, senão mesmo constrangimento ou mal-estar. J. de Sena, ao comentar os poemas editados pelo próprio autor, afirma: "creio firmemente que não são grande poesia, mas que há neles momentos de grande poesia. E que importam muito pelo que revelam do poeta Fernando Pessoa (ou do que o homem com esse nome possa interessar à elucidação da sua poesia), e por conterem, sobretudo os sonetos, muitos dos temas, ou praticamente todos, que ele desenvol-

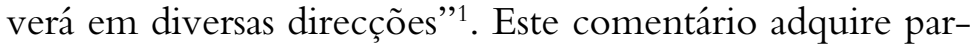
ticular interesse se pensarmos que também outros estudiosos têm sublinhado uma relação de continuidade, a nível temático, entre poesia em inglês e poesia em português ${ }^{2}$. O pro-

* Gianluca Miraglia é Investigador do Centro de Tradições Populares Portuguesas da Universidade de Lisboa. Licenciado em Línguas e Literaturas Modernas pela Universidade de Veneza e doutorado pela Universidade de Bolonha, tem-se dedicado à narrativa fantástica do século XIX, tendo editado Os contos de Álvaro de Carvalhal, e à obra de Garrett. Publicou textos inéditos de Pessoa e tem tratado o problema da tradução. Actualmente, estuda as relações entre literatura oral e literatura erudita.

1 J. de Sena, Fernando Pessoa \& $C^{a}$ heterónima, Lisboa, Edições 70, 2a ed., 1984, p. 407.

2 Cf. A. Terlinden, Fernando Pessoa: the bilingual portuguese poet, Bruxelles, 1990; L. Freire, Fernando Pessoa: entre vozes, entre línguas, Lisboa, Assírio \& Alvim, 2004. 
blema, estimulante e árduo, que se coloca ao crítico será então o de entender e explicar o motivo pelo qual a expressão dessa temática em língua portuguesa redunda numa das obras mais notáveis do século XX, enquanto a sua manifestação em língua inglesa atinge resultados estéticos menores ${ }^{3}$.

Uma das considerações mais recorrentes acerca da linguagem poética dos 35 sonnets, Antinous e Ephitalamium, refere que nestas composições o inglês é "complexo e ambicioso, além de por vezes excessivamente literário e até arcaizante"4. R. Zenith, em introdução a uma antologia para o público americano, nota que: "They do not fall well on modern ears. They never have the sparkle, the music, the colloquial verve, or the quiet elegance achieved at different points in his Portuguese output [...] Though Pessoa wrote excellent English for a foreigner, it lacked the organic fiber and carnal weight

3 X. da Silva descortina outros motivos por trás da desvalorização da poesia inglesa de Pessoa: "Es curioso observar que, no poco reveladoramente, desde el ámbito português en diferentes oportunidades se han subrayado, com llamativa parcialidad, sus limitaciones linguísticas al respecto [...] las razones de estas críticas no parecen excessivamente oscuras, dicha se la verdad, dado que no se hace complicado entender que el gesto de poner en duda la destreza lingüística del poeta a lo largo de su obra en inglés sirve, a todas luces, para legitimar la enajenación de sus textos en esta lengua en favor del sistema linguístico português"("La traducción según Fernando Pessoa (antologia de textos críticos"), Quaderns. Revista de traducción, 9, 2003, pp. 137-153; a citação é tirada da página 140). A ideia é brilhante, mas parece-me destituída de qualquer fundamento pois as críticas mais categóricas vieram desde sempre de escritores ou críticos de língua materna inglesa como Roy Campbell, E. Rouditi, e mais recentemente R. Zenith, cf J. Blanco, "Pessoa's first disseminators in English", Actas do IV Congresso Internacional de Estudos Pessoanos - secção norte-americana, Tulane University-New Orleans, Lousiana, 17 a 19 de Novembro de 1988, A. De Campos Brunetti (cord.), Porto, Fundação Eng. António de Almeida, 1991, pp. 9-17. Uma das primeiras apreciações críticas, senão mesmo a primeira, embora particular, deve ser considerada a de W. Bentley, em carta de 8 de Agosto de 1918, com interessantes comentários acerca dos sonetos e de Antinous, que se encontra no espólio, 115(1)-19.

${ }^{4}$ J.de Sena, op. cit., p. 317. 
of what is so aptly known as a mother tongue" ${ }^{5}$. O mesmo estudioso chega à conclusão que "contrary to what some scholars have supposed, Pessoa was not perfectly bilingual"6. Creio, porém, que a questão é mais complexa. Como sabemos, o escritor adquiriu na infância a língua portuguesa e sucessivamente, tendo-se transferido para a Africa do Sul com a família, aprendeu o inglês em idade escolar. Estamos, em terminologia técnica, perante um caso de bilinguismo consecutivo $^{7}$, em que a aprendizagem da L 2 foi tão profunda e definitiva que permitiu a Pessoa alcançar um notável êxito escolar na Durban High School e basear a sua vida profissional no domínio da língua inglesa. Acresce que o processo de formação, que é de facto uma aculturação no caso específico, ocorreu predominantemente nessa língua, e o levantamento da produção poética e ficcional até ao começo da primeira década do século XX demonstra de forma clara e inequívoca que, para Pessoa, era o inglês a língua mais natural e imediata para a criação literária. A vivência pessoana do bilinguismo apresenta um facto deveras notável, já salientado por vários críticos, ou seja o impacto que o conhecimento da língua inglesa teve na renovação da linguagem da poesia portuguesa levada a cabo por Pessoa através, em particular, de dois dos seus heterónimos: "curiosly enough, the poetry attributed to Caeiro e Campos has a certain directness of style that Pessoa brought into Portuguese from English, via Walt Whitman in particular. That directness is almost always lacking in his

${ }^{5}$ F. Pessoa, Selected poems, New York, Grove Press, 1998, p. 26.

6 Ivi, p. 25.

7 A bibliografia sobre o bilinguismo é muito vasta e numerosas são as definições do fenómeno (cf.o verbete de T. Mac Neil "bilinguisme/bilingualism", Dictionnaire Internacional des Termes Littéraires, www.ditl.info), prefiro lembrar, pela clareza e eficácia, a de R. Titone: "il bilinguismo consiste nella capacità di un individuo di esprimersi in una seconda lingua aderendo fedelmente ai concetti e alle strutture che a tale lingua sono propri, anzichè parafrasando la lingua nativa" (Bilinguismo precoce ed educazione bilingue, Armando, Roma, 1972, p. 13). 
English poetry, among which the sonnets deserve first prize for convolutedness". . Ao mesmo tempo, porém, não tem sido detectada uma paralela influência do português na sua expressão literária em língua inglesa.

O problema ter-se-á, então, de colocar não ao nível tout court da língua normal, mas sim ao da língua literária9. É um campo de análise ainda não devidamente explorado, talvez por exigir competências altamente específicas, e aqui limito-me a algumas sugestões para um futuro estudo. Na abordagem da poesia inglesa de Pessoa é necessário distinguir claramente entre textos como os dos 35 Sonnets, baseados numa poética que faz do desvio da língua comum a sua característica essencial, mercê do recurso contínuo a um léxico arcaico e a uma sintaxe complexa, e outros poemas, como é o caso dos reunidos no volume The Mad Fiddler, nos quais a linguagem utilizada resulta mais próxima do idioma comum ${ }^{10}$.

8 F. Pessoa, Selected poems, ibidem. J.de Sena chama a atenção para as "adjectivações sintagmáticas", a "substantivação dos verbos", os “desdobramentos, em português, do "caso possessivo" britânico"(op. cit., pp. 337-338).

9 Acerca do conceito de língua literária veja-se V.M., Aguiar e Silva, Teoria da literatura, Coimbra, Almedina, 1988 ( $8^{\mathrm{a}} \mathrm{ed}$.), pp. 144-173. Sobre o bilinguismo ou multilinguismo literário continua a ser referência obrigatória o livro de L. Forster, The poet's tongues: multilingualism in literature, Cambridge, 1970. Veja-se também as páginas dedicadas ao assunto por C. Guillen em L'uno e il molteplice: introduzione alla letteratura comparata (Entre lo uno y lo diverso. Introdución a la literatura comparada), Bologna, Il Mulino, 1992, pp. 360-380. Vale a pena, pela relevância no caso específico, citar esta observação de Guillen: "È ben noto, infatti, che l"'equilinguismo", o dominio identico di due mezzi linguistici di comunicazione, salvo eccezioni, come Samuel Beckett, è rarissimo. Ed è notevole il fatto che Beckett non è innanzitutto un poeta" (p. 361).

${ }^{10}$ Veja-se o comentário de L. Freire sobre os poemas reunidos em The Mad Fiddler: "estes textos [...] representam no seu todo o que de melhor e mais interessante Pessoa escreveu em inglês e reflectem, em relação à poesia anteriormente referida [i.e. a poesia editada in vita], uma maior fluência, naturalidade e liberdade formal, conquanto permaneça neles o sistema de rima, como, de resto, em toda a poesia inglesa" (F. Pessoa, Poesia inglesa (I), Lisboa, Assírio \& Alvim, 2000, p. 345). 
Para determinar a fluência e a naturalidade do inglês de Pessoa, há textos que se prestam a uma eficaz análise comparativa como é o caso das autotraduções dos primeiros 134 versos da "Ode Marítima", de algumas estrofes de "Opiário", e dos dois poemas "Tenho uma grande constipação" e "Apostilla"11.

Abrindo uma breve digressão, chamo a atenção para o facto de a análise das autotraduções ser de grande utilidade para uma melhor interpretação dos poemas mencionados e para esclarecer eventuais ambiguidades. $\mathrm{O}$ cotejo com o original pode até levar a descobertas surpreendentes como acontece em relação ao verso 104 da "Ode Marítima". Ao lermos o texto impresso no segundo número da revista Orpheu, que é testemunho único, pois não existe autógrafo, e mais precisamente os vv. 103-106, verificamos a repetição do termo 'ilhas' que suscita estranheza:

O soluço absurdo que as nossas almas derramam

Sobre as extensões de mares diferentes com ilhas ao longe,

Sobre as ilhas longínquas das costas deixadas passar,

Sobre o crescer nítido dos portos, com as suas casas e a sua gente, Para o navio que se aproxima.

11 Estes textos podem ser lidos na edição crítica de C. Berardinelli, Poemas de Álvaro de Campos, Lisboa, INCM, 1990, pp. 371-377. No livro de A. Saraiva, F. Pessoa poeta-tradutor de poetas (Porto, Lello Editores, 1996) a lista das traduções do português para inglês regista só os fragmentos de "Opiary" e "Naval Ode", e indica como data de publicação póstuma o ano de 1993, ou seja o volume organizado por T. R. Lopes, Pessoa Inédito (Lisboa, Livros Horizonte). Os dois textos, na realidade, já tinham sido editados três anos antes no citado Volume II da Edição Crítica de responsabilidade da Equipa Pessoa dirigida por Ivo Castro, e, além disso, "I have a bad cold" e "Make use of my time!" saíram em Presença, número único, em 1977. Cumpre avisar que na transcrição de "Naval Ode" em Pessoa Inédito há alguns erros de transcrição como 'suddle' por 'bustle' ou 'alones' por 'slopes'. Também a análise das traduções dos poemas de A. Botto seria com certeza proveitosa para avaliar a fluência do inglês pessoano. 
A descrição gradual, verso a verso, do derramar-se do soluço absurdo num movimento que vai das extensões do mar até ao porto, parece parar, senão mesmo inverter-se, no verso 104, em virtude da repetição da palavra 'ilhas' em dois sintagmas sinonímicos 'ilhas ao longe'/'ilhas longínquas'. A leitura da autotradução revela, como assinalou V. Figueiredo, uma modificação lexical ${ }^{12}$ :

The absurd sob that our souls spill

Over the ever-different tract of sea with islands afar,

Over the distant lines of the coasts we merely pass by,

Over the clear growing-clear of ports, with their houses and their people,

When the ship nears the land.

O que a aparente modificação demonstra, de forma inesperada e surpreendente após mais de 90 anos da publicação do poema e mais de 50 de exegese crítica, é nada mais nada menos que a existência dum erro. $\mathrm{O}$ testemunho indirecto permite emendar o texto impresso na revista Orpheu, e reproduzido em todas as edições sucessivas, no qual a substituição de 'linhas' com o termo 'ilhas' afigura-se ter sido, com muita probabilidade, um erro tipográfico, uma gralha, (a não ser que o próprio original entregue por Pessoa contivesse um lapso), que se deve à semelhança entre as duas palavras, uma é quase anagrama da outra, e ao facto de 'ilha' aparecer no

12 V. Figueiredo, "Fernando Pessoa e a tradução", Hermeneus: Revista de la Facultad de Traducción e Interpretación de Soria, 7, 2005. O comentário ao verso em causa é o seguinte: "Apenas uma vez neste fragmento (auto)traduzido da "Ode Marítima”, Fernando Pessoa toma uma liberdade que só poderia tomar um autotradutor: no verso 104 ele 'corrige' o original [...] aqui linhas das costas parece fazer mais sentido [...] daqui se depreende que a análise dos textos autotraduzidos pode ter produtividadde na fixação do texto original. No caso em apreço, esta possibilidade que o autor apresentou na autotradução deveria ser apresentada, pelo menos numa edição crítica, como uma variante". 
verso 103 , sendo que a substituição não redunda numa frase incorrecta ou ilógica, embora de sintaxe um tanto involuta ${ }^{13}$.

Voltando agora ao bilinguismo de F. Pessoa, os estudos consagrados a poesia inglesa não levantam a hipótese que o poeta se tivesse alguma vez apercebido de uma diferença substancial de valor estético entre o que escrevia em português e o que escrevia em língua inglesa, mormente no domínio da poesia. Os documentos transcritos em apêndice, todavia, parecem indicar o contrário. Sendo um deles, o texto $A$, já editado em obra de referência na bibliografia pessoana, explico, tomando a liberdade de me servir dumas memórias pessoais, o motivo da sua nova reprodução. Há cerca de vinte anos, com vista à edição de um conto inédito, passei largos meses a explorar numerosos envelopes do espólio conservado na Biblioteca Nacional ${ }^{14}$. Compulsei centenas se não milhares de papéis e vários textos, na altura ainda não divulgados, suscitaram a minha curiosidade, ou o meu interesse, quer pelo seu valor estético, quer pela relevância enquanto documentos valiosos para um conhecimento mais íntimo do homem que criou tão extraordinária obra. A leitura emocionada do rascunho duma carta em inglês (o texto

13 Acerca dos erros do codex unicus e sobre a edição de autógrafos, ou de testemunhos únicos veja-se A. Stussi, Nuovo avviamento agli studi di filologia italiana, Bologna, Il Mulino, 1988, pp. 105-111 e pp.157- 164. Em português, pode ler-se com proveito o artigo de I. Castro, "A 'tragédia das Flores ou a arte de editar os manuscritos autógrafos”, Boletim de Filologia, Tomo XXVI, 1980/81, pp. 309-359.

14 O conto era "The case of the science master" e foi publicado na Revista da Biblioteca Nacional, S.2, vol. 3 (3), 1988, pp. 43-72. Dessa investigação resultaram também uma nota que emendava a errónea datação de um diário de leituras por longo tempo considerado de 1903, sendo, na realidade de 1906, "Fernando Pessoa: diários da terceira adolescência”, Revista da Biblioteca Nacional, cit., pp. 258-260; e a publicação de um texto sobre Orpheu: "Fernando Pessoa, Um texto inédito: É só pelo inferior - o banal, o fictício, o extravagante - que agimos sobre a nossa época", Colóquio-Letras, n.125-126, Julho-Dezembro de 1992, pp. 193-198. 
A no apêndice), é uma das lembranças mais marcantes que guardo desse período de investigação.

A humildade com que o autor da missiva, através de expressões prudentes e cautelosas, procura estabelecer uma relação de confiança com o destinatário e a confissão do desalento e do desnorte de quem vê desmoronar o sonho, desde há muito acalentado, de se tornar um poeta afirmado e porventura célebre em Inglaterra, tornam este documento um dos textos íntimos mais notáveis do espólio pessoano. Como veremos em detalhe infra, o motivo que está na origem da carta é a rejeição 'sumária' dum volume de poemas que Pessoa enviara a um editor inglês; rejeição arrasadora e dificil de aceitar e compreender porque as custas de edição seriam a cargo do próprio autor. "The summary kind of rejection which the poems thus offered received, has led me to a very hesitating attitude towards them", escreve Pessoa, expressando de forma inequívoca o abalo que o "absolute contempt" reservado aos poemas, e com que decerto nunca teria contado, provocara nele. Perante o inesperado evento, Pessoa sente a necessidade de outra opinião, de uma crítica franca que dissipe a sua hesitação. Tocante é a atitude submissa de quem escreve a carta, consciente de se sujeitar a uma prova, um exame que poderia redundar numa nova humilhação.

$\mathrm{Na}$ altura, chamei a atenção de alguns amigos, então empenhados em trabalhos sobre a poesia inglesa de Pessoa, para o teor desta carta, mas por um motivo ou por outro nenhum deles acabou por publicá-la, na íntegra ou parcialmente. Eu também, pouco depois, iria dedicar-me a outras pesquisas e nos anos seguintes alheei-me dos estudos pessoanos, procurando só manter-me ao corrente das novas edições que iam sendo publicadas pela Equipa Pessoa e pela Assírio \& Alvim. Por isso tudo, assim que tive entre mãos a edição da Correspondência organizada por Manuela Parreira da Silva, procurei avidamente a carta que tanto me 
impressionara quando a descobrira no microfilme do envelope 141. E lá estava, nas páginas 186 e 187, a transcrição, seguida da respectiva tradução para português. A releitura do documento confirmou de imediato a ideia da sua relevância, que perdurara ao longo dos anos na minha memória, e com curiosidade expectante abri as páginas finais do livro para ler a nota consagrada ao documento número 84. Estupefacto, deparei com um lacónico comentário: “Destinatário não identificado. A referência aos poemas rejeitados por outro editor remetem-nos para as cartas seguintes presumivelmente de 1915, a Frank Palmer e Harold Monro, bem como a carta de 23-10-1915, a John Lane" 15 . A incredulidade perante a desvalorização deste testemunho, que sempre julgara fundamental para a compreensão quer do bilinguismo de Fernando Pessoa, quer de certas opções por ele tomadas em relação à sua produção literária, daria lugar sucessivamente a uma profunda perplexidade acerca da leitura crítica dada por Manuela Parreira da Silva desta carta no ensaio Realidade e ficção, perplexidade ainda maior tendo em conta que, no seu complexo, o volume revela uma notável perspicácia na análise de outros documentos e que faz jus ao subtítulo "para uma biografia epistolar de Fernando Pessoa":

Esta preferência ou este relevo dado aos seus poemas em inglês e à auto-propaganda está em perfeita conformidade com uma plena consciência do valor e alcance universal da sua poesia. Mas Pessoa procura com avidez quem avalie seriamente a sua obra, precisa de uma confirmação internacional, já que, em Portugal, a inexistência de uma crítica credível (como as reacções a Orpheu amplamente lhe mostram) o deixa quase a sós consigo. John Lane não iria, porém, corresponder a esta neces-

15 F. Pessoa, Correspondência (1905-1922), Lisboa, Assírio\&Alvim, 1998, p. 438 . 
sidade. A tristeza sentida por Pessoa está, aliás, bem expressa numa outra carta, não datada e sem identificação do destinatário, a quem afirma ter enviado o seu conjunto de poemas a um editor inglês que o rejeitou, embora ele próprio se tenha proposto pagar a edição. A rejeição dos poemas, tê-lo-á deixado algo hesitante quanto ao valor. Estou, porém, em crer que se trate apenas aqui de falsa modéstia, até porque, mais adiante, confessa ser não tão orgulhoso que recuse uma crítica pouco favorável, mas também "not so humble as to accept it altogether ${ }^{16}$

O que mais surpreende nesta passagem é que, ao desvalorizar a carta, passa-se total e inexplicavelmente ao lado de um acontecimento biográfico que um dos mais interessantes livros publicado nos últimos anos (pela mesma editora, que prima por rigor e competência, e curiosamente com preciosa colaboração de M. Parreira da Silva), Escritos autobiográficos, automáticos e de reflexão pessoal, organizado por $\mathrm{R}$. Zenith, em 2003, ou seja um ano antes de Realidade e fiç̧ão, destaca entre entre os acontecimentos marcantes do ano de 1917:

Envia The Mad Fiddler, um livro de poemas, a uma editora inglesa, Constable\&Company Lrd., que recusa a sua publicação numa carta datada de 6 de Junho. ${ }^{17}$

Perante o silêncio da Correspondência, procuramos, então, recolher os elementos que nos ajudam a enquadrar no tempo a carta e a entendê-la melhor ${ }^{18}$. Não parece haver dúvidas que a sua origem está na recusa da publicação dos poemas comunicada de forma lacónica:

16 Silva, M. Parreira da, Realidade e fiç̧ão: para uma biografia epistolar de Fernando Pessoa, Lisboa, Assírio \& Alvim, 2004, p. 261. O sublinhado é meu.

17 Op. cit., p. 505.

18 Para o efeito revela-se de grande utilidade a introdução de M. Angioni e F. Gomes a F. Pessoa, Poemas Ingleses. Tomo III, The Mad Fiddler, Lisboa, INCM, 1999. 


\section{Dear Sir,}

We regret that, after very careful consideration, we do not see our way to undertaking the publication of your poems "THE MAD FIDDLER, etc." which we therefore return. Thanking you none the less for giving us an opportunity of considering them,

We remain,

\section{Yours faithfully ${ }^{19}$}

Em 1915, F. Pessoa enviara a John Lane, o editor da revista Blast: Review of The Great English Vortex, 16 poemas, "fifteen of which are representative of the work contained in a book of English poems I have written". Com muita probabilidade, o livro em questão é The Mad Fiddler, recolha de poemas que na altura "era constituída por uma trintena de poemas", como nos informam M. Angioni e F. Gomes, que aliás chamam a atenção para "uma tocante passagem reveladora da insegurança do autor" 20 , em que Pessoa pede ao editor para ler mais do que uma vez os poemas antes de formular uma opinião definitiva. No espólio existem também dois rascunhos de uma carta enviada a H. Monro, M. Parreira da Silva opta por editar só um dos documentos, sem dar a conhecer esta variante de grande relevo: "I am sending you herewith a very small typescript of poems concerning which I should be obliged if you would inform me if you can publish them, or would be ready to, the expenses of the edition being paid by me [...] if you are willing to publish the book, please inform me of the price, and for what number of copies, for the determination of that I leave to you" ${ }^{21}$. Estas frases parecem indicar uma relação directa entre a carta e a recusa da publicação por parte da editora inglesa, todavia,

19 A carta, já dada a conhecer por A. Terlinden, encontra-se no espólio com a cota 71-83.

20 Op. cit., p. 14.

21 114(2)-90. 
para ter a certeza absoluta, seria necessário esclarecer as relações entre H. Monro e a editora Constable \& Company, sem excluir a possibilidade de Pessoa ter feito a proposta de edição de The Mad Fiddler a mais de um editor. Se, de facto, se confirmar a relação directa então a datação proposta por M. Parreira da Silva, o ano de 1915, afigura-se pouco provável, pois teríamos de supor um período demasiado longo entre o pedido e a resposta, embora o decorrer da Primeira Guerra Mundial possa justificar a demora.

Incorrecta é, sem dúvida, a data de 1915 para o documento que estamos a analisar, dado que só poderia ter sido escrito após a recusa de edição. Não é claro o motivo que leva M. Parreira da Silva a identificar o destinatário com 'um editor inglês', e na nota não é apresentado nenhum argumento para tal identificação. No estado actual da pesquisa, pode afirmar-se que a carta é endereçada a uma pessoa de língua inglesa e com a qual Pessoa devia ter um relacionamento suficientemente íntimo para que lhe fosse possível partilhar a sua decepção e formular o pedido de uma crítica franca acerca dos seus poemas. No espólio existe outro rascunho de carta, não editado na Correspondência (no apêndice é o texto $B$ ), que aparenta semelhanças com este documento na sua parte inicial, enquanto os comentários sobre a eventual estranheza do inglês utilizado nos poemas encontram paralelo em trechos da carta enviada em 1915 a J. Lane, e, por outro lado, não há alguma alusão à recusa da publicação do livro. É mais um testemunho, de todos os modos, da hesitação de Pessoa a respeito do valor da sua poesia inglesa e da sua necessidade de encontrar um interlocutor que pudesse dissipar as suas dúvidas. Destaca-se, no texto, uma curiosa referência à astrologia que deixa supor que o destinatário partilhava o mesmo interesse de Pessoa pela disciplina.

Para concluir, algumas reflexões sobre o impacto que a recusa da publicação de The Mad Fiddler teve no poeta. A mais directa consequência é o facto dele ter deixado inédito este 
volume de versos, apesar de editar em anos seguintes outros poemas ingleses. Em segundo lugar, como nos informa um profundo conhecedor do espólio pessoano, R. Zenith: “After 1916, Pessoa's creative writing was largely confined to Portuguese, though still used English for an occasional poem and rather extensively for his personal notes"22. Esta observação não se aplica unicamente à criação poética, também na ficção, é o caso dos contos policiais, verifica-se a passagem de uma primeira fase de escrita em língua inglesa para uma segunda em português ${ }^{23}$. Esta opção pela língua portuguesa radica, creio, na percepção que o seu destino de escritor estava traçado nela, sem que lhe fosse possível compreender a fundo a razão disso. O que é certo é que a frase do texto A, transcrita a seguir, revela de forma inequívoca como o "absolute contempt", em 1917, instalou na mente de Pessoa a dúvida acerca do real valor do que escrevia em língua inglesa, dúvida para ele inexplicável justamente à luz do bom acolhimento reservado às composições já publicadas em português, e que provavelmente o acompanhou até ao fim da vida:

What I have written in Portuguese has been very generally followed, though I have published no more than in reviews.

${ }^{22}$ F. Pessoa, Fernando Pessoa \& Co, cit, p. 26. J. Pizarro, ao comentar um conhecido trecho pessoano sobre o uso diferenciado do inglês e do português, comunica-me que "se podria sugerir que la propuesta de dejar el inglés como lengua internacional y pública y el portugués como lengua universal y privada, corresponde a la posición de alguien que ya sentia (hacia fines o princípios de los veinte) que no le fluian tanto las palabras en un idioma como en el outro. Que podria ser mas creativo en una lengua, mientras en la outra era menos espontaneo".

23 Cf. G. Miraglia, "Pessoa e il giallo", Delitti di Carta, Nuova Serie, n 2, maggio 2004, pp.61-72. Veja-se também a introdução de S. Celani a F. Pessoa, Il caso Vargas, Roma, Il Filo, 2006. 


\section{APÊNDICE}

\section{Texto A [114(1)-112]}

Sir:

I am quite aware that there is no species of excuse for the request that I am going to make; so I will make no excuse for it. There is, however, an explanation, and I hope the patience you may be able to give it will lead you afterwards to give it to the details that follow.

The typescript of poems which I am sending you together with is letter has been offered by me to an English publisher, and rejected; the occurrence, though usual enough, becomes less usual owing to the fact that, as I had not been insane as to propose that he should publish it as his own risk, all I had done was to ask if could publish it on my paying the cost of the publication.

The summary kind of rejection which the poems thus offered received, has led me to a very hesitating attitude towards them. Though I never conceived them good, I have never thought they would have been deserving of an absolute contempt.

I send you the book and would be much obliged if you could give me your opinion on it. I am secluded and deprived of all kind of relationship that might exert some criticism on what I write. I am neither so proud as to despise altogether an opinion other than my own, nor so humble as to accept it altogether. But I []

What I have written in Portuguese has been very generally followed, though I have published no more than in reviews []

I am quite aware that, as I have said, there is no excuse for this intrusion on your time and your patience. Yet I am led thus to trespass upon them because I have no one on whom I can depend for an impartial criticism of what I write in Portuguese, and I live in Portugal; it is far more difficult to obtain it for anything written in English. Will you do me the favour of giving me your opinion?

To the book itself I have added three long poems, being convinced that [] The short poems contained in my book give no opportunity of showing any technique of construction [] 


\section{Texto B [114(1)-90]}

Few things are excusable for which an excuse is asked. And the present letter, which acts as an excuse for sending you the poems enclosed, cannot plead an alibi from that imputation.

The fact is, however, to put things as simply as possible, that, finding myself to have written these poems, I am naturally desirous of having on them an opinion quite exterior to mine, and different from it; it has occurred to me - no doubt on some hour in which an evil transit took place in your horoscope - that I could send them to you, having no one, personally known to me, whom I could more excusably trouble with the request.

I do not think, however, that the poems need inconvenience you very much, inasmuch as a cursory glance at them will at once either be, once for all, the real excuse for my sending them and the compensation for your trouble ( and this venture to hope ), or it will speedy bring that disgust which - because it is speedy - is a as little uncomfortable as possible.

I should indeed like to have your opinion on these poems. I cannot promise, of course, to agree with it, or to think about it the precise things you yourself have thought. It interests me, however, to have it, and the few lines in which I hope it will be possible for you to convey it would go far to give me an exterior notion of myself which even a dramatic vision of things finds it difficult to seduce itself into having.

The grammar and the phrasing of these compositions will seem to you at times rather strange. And, as the poems, after all, are written by a foreigner, you will feel inclined to attribute them (these singularities) to an imperfect acquaintance with the language (Eng. Language) and that hardihood that is the child of all ignorance. This, however, is not the right notion, for, as far as language goes, you may consider me as English as any Englishman, and, as to the strangeness and abnormality, you will have had ample experience of the illogical tendencies of all modern poetry to prove me guilty, not of [] in where Englishmen fear to tread, but of painting Parnassus red, to use an entirely violent and improper, though fitting, expression. 